\title{
Apparent Affinity Estimates and Reversal of the Effects of Synthetic Cannabinoids AM-2201, CP-47,497, JWH-122, and JWH-250 by Rimonabant in Rhesus Monkeys
}

\author{
Lenka Hruba and Lance R. McMahon
}

Department of Pharmacology, University of Texas Health Science Center at San Antonio, San Antonio, Texas

Received February 3, 2017; accepted May 19, 2017

\begin{abstract}
Synthetic cannabinoids have been prohibited due to abuse liability and toxicity. Four such synthetic cannabinoids, AM-2201 ([1-(5-fluoropentyl)indol-3-yl]-naphthalen-1-ylmethanone), CP-47,497 (2-[(1R,3S)-3-hydroxycyclohexyl]-5-(2-methyloctan-2-yl)phenol), JWH-122 [(4-methylnaphthalen-1-yl)-(1-pentylindol-3-yl)methanone], and $\mathrm{JWH}-250$ [2-(2-methoxyphenyl)-1-(1-pentylindol-3-yl)ethanone], were tested for their capacity to produce $\mathrm{CB}_{1}$ receptor-mediated discriminative stimulus effects in two groups of rhesus monkeys. One group $(n=4)$ discriminated $\Delta^{9}$-tetrahydrocannabinol $\left(\Delta^{9}-\mathrm{THC}\right.$; $0.1 \mathrm{mg} / \mathrm{kg}$ i.v.), and a second group $(n=4)$ discriminated the cannabinoid antagonist rimonabant (1 $\mathrm{mg} / \mathrm{kg}$ i.v.) while receiving $1 \mathrm{mg} / \mathrm{kg} / 12$ hours of $\Delta^{9}$-THC. AM-2201, JWH-122, CP-47,497, $\mathrm{JWH}-250$, and $\Delta^{9}-\mathrm{THC}$ increased $\Delta^{9}-\mathrm{THC}$ lever responding. Duration of action was 1-2 hours for AM-2201, JWH-122, and JWH-250 and $4-5$ hours for CP-47,497 and $\Delta^{9}-$ THC. Rimonabant $(1 \mathrm{mg} / \mathrm{kg})$ surmountably antagonized the discriminative stimulus effects of all cannabinoid agonists; the magnitude of rightward shift
\end{abstract}

\section{Introduction}

Synthetic cannabinoid $\mathrm{CB}_{1}$ and $\mathrm{CB}_{2}$ receptor agonists marketed under various brand names (e.g., Spice or K2) have been sold and abused worldwide since 2008 (Auwärter et al., 2009; Vardakou et al., 2010). These products typically contain at least one synthetic cannabinoid and do not contain cannabis or its primary psychoactive drug $\Delta^{9}$-tetrahydrocannabinol $\left(\Delta^{9}\right.$-THC). The rise in abuse was due in part to synthetic cannabinoids being legal prior to being placed under Schedule 1 of the Controlled Substances Act of the United States (Drug Enforcement Administration, 2011). Several countries have since prohibited synthetic cannabinoids originally detected in Spice/K2 and related products, including JWH-018 [naphthalen-1-yl-(1-pentylindol-3-yl) methanone], JWH-073 [(1-butylindol-3-yl)-naphthalen-1-ylmethanone], CP-47,497

This work was supported by the National Institutes of Health National Institute on Drug Abuse [Grant DA19222].

https://doi.org/10.1124/jpet.117.240572. was 10.6-fold for AM-2201, 10.7-fold for JWH-122, 11.0-fold for $\mathrm{CP}-47,497$, and 15.7 -fold for $\mathrm{JWH}-250$. The respective $\mathrm{pK}_{\mathrm{B}}$ values were not significantly different: $6.61,6.65,6.66$, and 6.83. In $\Delta^{9}$-THC-treated monkeys discriminating rimonabant, AM-2201 (0.1 and $0.32 \mathrm{mg} / \mathrm{kg}), \mathrm{JWH}-122(0.32$ and $1 \mathrm{mg} / \mathrm{kg})$, $\mathrm{JWH}-250$ ( 1 and $3.2 \mathrm{mg} / \mathrm{kg}$ ), and CP-47,497 (0.32, 1, and $3.2 \mathrm{mg} / \mathrm{kg})$ produced not only rate-decreasing effects that were reversed by rimonabant, but also dose-dependent, rightward shifts in the rimonabant discrimination dose-effect function. These results show striking similarity in the $\mathrm{CB}_{1}$ receptor mechanism mediating the subjective effects of AM-2201, JWH-122, JWH-250, and CP-47,497. For products containing AM-2201 and JWH-122, a short duration of action could lead to more frequent use; moreover, inattention to differences in potency among synthetic cannabinoids could underlie unexpected toxicity. Rapid reversal of effects by intravenous rimonabant has potential value in emergency situations.

ABBREVIATIONS: AM-2201, [1-(5-fluoropentyl)indol-3-yl]-naphthalen-1-ylmethanone; ANOVA, analysis of variance; CP-47,497, 2-[(1R,3S)-3hydroxycyclohexyl]-5-(2-methyloctan-2-yl)phenol; FR, fixed ratio; HU-210, (6aR,10aR)-9-(hydroxymethyl)-6,6-dimethyl-3-(2-methyloctan-2-yl)-6a,7,10,10atetrahydrobenzo[c]chromen-1-ol; JWH-018, naphthalen-1-yl-(1-pentylindol-3-yl) methanone; JWH-073, (1-butylindol-3-yl)-naphthalen-1-ylmethanone; JWH-122, (4-methylnaphthalen-1-yl)-(1-pentylindol-3-yl)methanone; JWH-250, 2-(2-methoxyphenyl)-1-(1-pentylindol-3-yl)ethanone; $\Delta^{9}$-THC,

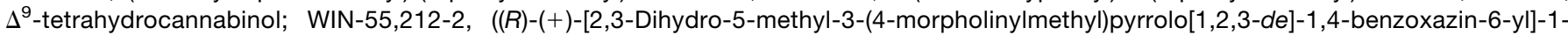
naphthalenylmethanone mesylate. 
$\Delta^{9}$-tetrahydrocannabinol<smiles>CCCCCc1cc(O)c2c(c1)OC(C)(C)C1CCC(C)=CC21</smiles><smiles>CCCCCCC(C)(C)c1ccc(C2CCCC(O)C2)c(O)c1</smiles>
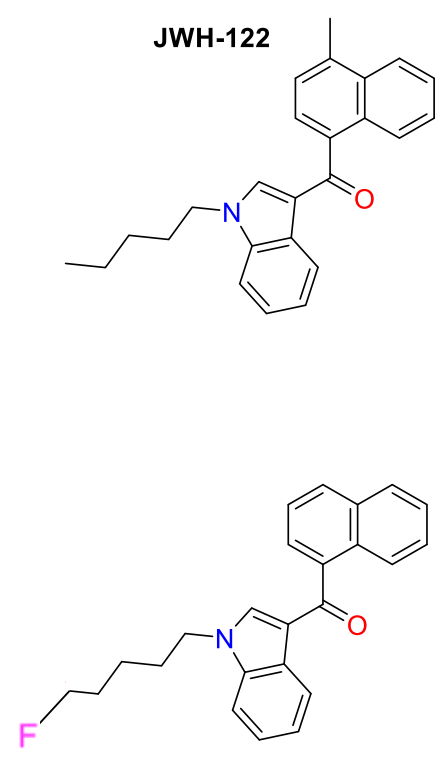

AM-2201<smiles>CCCCCn1cc(C(=O)Cc2ccccc2OC)c2ccccc21</smiles><smiles>CCCCCn1cc(C(=O)c2cccc3ccccc23)c2ccccc21</smiles>

JWH-018
Fig. 1. Chemical structures of $\Delta^{9}-\mathrm{THC}$ and the five synthetic cannabinoids studied here; these synthetic cannabinoids were among the first to be identified in products sold and abused for psychoactive effects.
Figure 1 shows the structures of AM-2201, JWH-122, JWH250, and CP-47,497, along with $\Delta^{9}$-THC and JWH-018. The synthetic cannabinoids (i.e., all but $\Delta^{9}$-THC) are divided into three distinct chemical groups. AM-2201, JWH-122, and JWH-018 are naphthoylindoles (Makriyannis and Deng, 2001, 2007; Huffman et al., 2003). JWH-250 does not have the naphthalene ring present in JWH-122 and AM-2201, but instead has a 2'-methoxy-phenylacetyl group in that position, i.e., it is a phenylacetylindole (Huffman et al., 2005). CP-47,497 is a cyclohexylphenol, which lacks the pyran ring of $\Delta^{9}$-THC and other tricyclic terpenoid derivatives (Palmer et al., 2002). CP-47,497 is a cannabinoid $\mathrm{CB}_{1}$ and $\mathrm{CB}_{2}$ receptor agonist that produces effects typical of cannabinoid agonists, such as hypolocomotion, analgesia, hypothermia, catalepsy, and cannabinoidlike discriminative stimulus effects in rodents (Weissman et al., 1982). AM-2201, JWH-122, and JWH-250 were demonstrated to produce $\Delta^{9}$-THC-like discriminative stimulus effects in rodents (Gatch and Forster, 2014, 2016), suggesting that they produce cannabis-like subjective effects in humans.

Drug discrimination assays in nonhuman primates were used to test the hypothesis that the in vivo effects of CP-47,497, AM-2201, JWH-122, and JWH-250 are mediated by the same receptor type (i.e., $\mathrm{CB}_{1}$ ) but differ in potency and time course. One group of rhesus monkeys $(n=4)$ discriminated $\Delta^{9}$-THC $(0.1 \mathrm{mg} / \mathrm{kg}$ i.v. $)$, and a second group of rhesus monkeys $(n=4)$ discriminated rimonabant $(1 \mathrm{mg} / \mathrm{kg}$ i.v. $)$ while receiving chronic $\Delta^{9}-\mathrm{THC}(1 \mathrm{mg} / \mathrm{kg} / 12$ hours s.c.). Quantitative analysis of antagonism by rimonabant was conducted. Previously, Schild analysis and single-dose apparent affinity estimates with rimonabant suggested that $\Delta^{9}$-THC, JWH018, and JWH-073 produced subjective effects through a common receptor site (Ginsburg et al., 2012; Rodriguez and McMahon, 2014). HU-210, on the other hand, required significantly larger doses of rimonabant to both prevent and reverse its effects (Hruba and McMahon, 2014). These results, in conjunction with the exceedingly long duration of action of HU-210 (i.e., 24-48 hours), were attributed to pseudoirreversible cannabinoid receptor binding. In the current study, rimonabant was administered prior to synthetic cannabinoids, and $\mathrm{pK}_{\mathrm{B}}$ values were calculated in monkeys discriminating $\Delta^{9}$-THC. Attenuation of the effects of rimonabant by synthetic cannabinoids was examined in monkeys discriminating rimonabant while receiving $\Delta^{9}$-THC daily. The rimonabant discrimination assay in $\Delta^{9}$-THC-treated monkeys appears to reflect the discrimination of $\Delta^{9}$-THC (i.e., vehicle training) versus the absence of $\Delta^{9}$-THC or a smaller dose of $\Delta^{9}$-THC (i.e., rimonabant training) (McMahon, 2006b), and there is further evidence that the discrimination is related to rimonabant-induced $\Delta^{9}$-THC withdrawal (Stewart and McMahon, 2010).

\section{Materials and Methods}

\section{Subjects}

Two female and two male adult rhesus monkeys (Macaca mulatta) discriminated $\Delta^{9}$-THC from vehicle. One female and three male adult rhesus monkeys discriminated rimonabant while receiving chronic $\Delta^{9}$-THC ( $1 \mathrm{mg} / \mathrm{kg} / 12$ hours s.c.). The monkeys were housed individually in stainless-steel cages on a 14-hour light/10-hour dark schedule (lights on at 6:00 a.m.). They were maintained at 95\% free-feeding weight (range $6.0-11.8 \mathrm{~kg}$ ). The diet consisted of primate chow (High Protein Monkey Diet; Harlan Teklad, Madison, WI), fresh fruit, and peanuts; water was provided in the home cage. Monkeys received cannabinoids in previous studies (Ginsburg et al., 2012; Hruba and McMahon, 2014). Experimental protocols were approved by the Institutional Animal Care and Use Committee, University of Texas Health San Antonio, and adhered to the Guide for the Care and Use of Laboratory Animals (2011).

\section{Surgery}

Monkeys were anesthetized with ketamine (10 mg/kg i.m.) followed by isoflurane (1.5-3.0\% inhaled via facemask). A catheter (heparincoated polyurethane; o.d. $=1.68 \mathrm{~mm}$, i.d. $=1.02 \mathrm{~mm}$; Instech Laboratories, Plymouth Meeting, PA) was inserted into a subclavian or femoral vein and secured to the vessel with suture silk (coated vicryl; Ethicon Inc., Somerville, NJ). The catheter extended from the 
vessel to the midscapular region of the back and was attached to a vascular access port located s.c. (Mida-cbas-c50; Instech Laboratories).

\section{Apparatus}

Monkeys were seated in chairs (model R001; Primate Products, Miami, FL) and placed in ventilated, sound-attenuating chambers equipped with two levers and two lights, one positioned above each lever. Feet were fastened onto brass plates that could receive a brief electric stimulus ( $3 \mathrm{~mA}, 250 \mathrm{~ms}$ ) delivered from an a.c. generator (Coulbourn Instruments, Allentown, PA). Experimental events were controlled and recorded with Med-PC software (MED Associates, St. Albans, VT) loaded onto a computer that was connected to the operant conditioning chambers via an interface (MED Associates)

\section{Drug Discrimination Training}

Monkeys discriminated $\Delta^{9}$-THC $(0.1 \mathrm{mg} / \mathrm{kg}$ i.v.) from vehicle (1 part absolute ethanol, 1 part emulphor-620, and 18 parts saline) while responding under a fixed ratio 5 (FR5) schedule of stimulus-shock termination. Four other monkeys received $1 \mathrm{mg} / \mathrm{kg}$ s.c. $\Delta^{9}$-THC at 6:15 a.m. and again at 6:15 p.m. and discriminated rimonabant $(1 \mathrm{mg} / \mathrm{kg}$ i.v.) from vehicle at 12:15 p.m. under an FR5 schedule of stimulusshock termination.

The experimental sessions were subdivided into consecutive 10-minute, multiple cycles; each cycle began with a 5 -minute timeout. There was no programmed consequence for responding during time-outs. After the time-out, there was a 5-minute schedule of stimulus-shock termination signaled by illumination of red lights. Five consecutive responses on the correct lever turned off the red lights, temporarily prevented the electric stimulus, and led to a 30-second time-out. Otherwise, an electric stimulus was scheduled for delivery every 40 seconds in monkeys discriminating $\Delta^{9}$-THC and 10 seconds in monkeys discriminating rimonabant. If monkeys responded on the incorrect lever, the response requirement was reset. The correct levers were nonsystematically assigned among monkeys (e.g., left lever was associated with the training dose of the training drug; right lever was associated with vehicle), but once assigned, they were permanent for each monkey.

Training sessions consisted of three to six cycles. Drug training entailed infusion of $\Delta^{9}$-THC $(0.1 \mathrm{mg} / \mathrm{kg}$ i.v. $)$ or rimonabant $(1 \mathrm{mg} / \mathrm{kg}$ i.v.) in the first minute of the first of three cycles; sham (dull pressure applied to the skin overlying the vascular access port) was administered in the first minute of the subsequent cycles. Vehicle training entailed infusion of vehicle in the first minute of the first cycle followed by vehicle or sham in subsequent cycles for a maximum of six cycles. Zero to three $\Delta^{9}$-THC or rimonabant training cycles were preceded by zero to three vehicle-training cycles. Five consecutive responses on the correct lever were required for reinforcement during each training cycle. Monkeys previously satisfied the following testing criteria: 1) greater than $80 \%$ of the total responses occurred on the correct lever, 2) fewer than five responses occurred on the incorrect lever before completion of the first FR on the correct lever, and 3) both occurred for all cycles during five consecutive or six of seven training sessions. Subsequent tests were conducted after performance satisfied the test criteria for two consecutive training sessions, including both vehicle and drug training sessions. The order of training with drug or vehicle was nonsystematic.

\section{Drug Discrimination Testing}

$\Delta^{\mathbf{9}}$-THC Discrimination. During test sessions, five consecutive responses on either lever postponed the shock schedule. The doseresponse function for $\Delta^{9}$-THC was determined by administering vehicle in the first cycle followed by doses of $\Delta^{9}$-THC increasing by 0.5 log units in subsequent cycles. Substitution tests were conducted by administering vehicle in the first cycle followed by doses of a test drug increasing by $0.5 \mathrm{log}$ units in subsequent cycles. The test drugs were CP-47,497, JWH-122, JWH-250, and AM-2201. The dose-effect function included an ineffective dose (i.e., dose resulting in less than $20 \%$ of responses on the training drug-appropriate lever) up to a dose producing greater than $80 \%$ of responses on the $\Delta^{9}$-THC lever. To establish a time course for $\Delta^{9}$-THC and the test drugs, the smallest dose of each producing greater than $80 \% \Delta^{9}$-THC appropriate responding was administered at the beginning of a cycle. Subsequent 5 -minute test sessions were conducted on the same day at 30 minute, 60 minute, and thereafter in 1-hour increments post-injection. Each 5 -minute test was preceded by a 5-minute timeout during which monkeys received either vehicle or sham non-systematically. Tests were conducted at 1-hour intervals until $\Delta^{9}$-THC appropriate responding was less than $20 \%$. To examine antagonism of $\Delta^{9}$-THC or a test drug, rimonabant ( $1 \mathrm{mg} / \mathrm{kg}$ i.v.) was administered in the first cycle followed by cumulative doses of a cannabinoid agonist in subsequent cycles.

Rimonabant Discrimination. During test sessions, five consecutive responses on either lever postponed the shock schedule. The dose-response function for rimonabant was determined by administering vehicle in the first cycle followed by doses of rimonabant increasing by $0.5 \mathrm{log}$ units in subsequent cycles. To examine attenuation of the rimonabant discriminative stimulus, a dose of test drug was administered in combination with rimonabant doses. CP-47,497 was studied by administering one of three doses $(0.32,1$, and $3.2 \mathrm{mg} / \mathrm{kg}$ ) in the first cycle followed by doses of rimonabant increasing by $0.5 \mathrm{log}$ units in subsequent cycles. AM-2201, JWH-122, and JWH250 had a relatively short duration of action. Therefore, a dose of each of these test drugs was administered in combination with vehicle or rimonabant at the beginning of a single-cycle test. AM-2201 was studied at 0.1 and $0.32 \mathrm{mg} / \mathrm{kg}$. JWH-122 and JWH-250 were studied at 0.32 and $1 \mathrm{mg} / \mathrm{kg}$. Rimonabant was studied from ineffective doses up to doses that produced greater than $80 \%$ of responses on the rimonabant lever or up to a dose of $5.6 \mathrm{mg} / \mathrm{kg}$, whichever occurred first. Due to limitations in the solubility of rimonabant in the vehicle and volume used for i.v. administration, $5.6 \mathrm{mg} / \mathrm{kg}$ was the largest dose studied. The order of testing with the various doses of cannabinoid agonists and rimonabant, alone and in combination, was nonsystematic.

\section{Drugs}

$\Delta^{9}$-THC (100 mg/ml in absolute ethanol) and rimonabant (Research Technologies Branch, National Institute on Drug Abuse, Rockville, MD), AM-2201 (Cayman Chemical Company, Ann Arbor, MI), JWH122 (Cayman Chemical Company), CP-47,497 (Cayman Chemical Company), and JWH-250 (Arch Pharm, Inc., Libertyville, IL) were dissolved in a mixture of 1 part absolute ethanol, 1 part emulphor-620 (Rhodia Inc., Cranbury, NJ), and 18 parts physiologic saline and administered intravenously in a volume of 0.1 to $1 \mathrm{ml} / \mathrm{kg}$. Doses were expressed as the weight of the previously listed forms in milligrams per kilogram of body weight.

\section{Data Analyses}

Discrimination data were expressed as a percentage of responses on the drug lever out of the total number of responses on both the drug and vehicle levers. Rate of responding on both levers (i.e., drug and vehicle) was calculated as responses per second, excluding responses during time-outs. Rate of responding during a test was expressed as the percentage of the control response rate for individual animals. The control was defined as the average response rate for all cycles during the five previous vehicle training sessions, excluding sessions during which the test criteria were not satisfied. Discrimination and rate data were averaged among subjects, separately per training drug, and were plotted as a function of dose and time.

To estimate the $\mathrm{ED}_{50}$ value, or dose producing $50 \%$ responding on the drug lever, individual dose-response data were analyzed with linear regression (Prism version 5.0 for Windows; GraphPad Software Inc., San Diego, CA). The analyses included doses spanning the linear portion of the dose-response function, and a common, best-fitting slope was used for further analyses (Kenakin, 1997). Doses corresponding to 
the $50 \%$ level of effect $\left(\mathrm{ED}_{50}\right.$ value), potency ratios, and their $95 \%$ confidence limits were calculated by parallel line analyses of data from individual subjects (Tallarida, 2000). The $\mathrm{ED}_{50}$ values were compared by calculating potency ratios for individual subjects. $\mathrm{ED}_{50}$ values were considered significantly different when the $95 \%$ confidence limits of the potency ratio did not include 1 . For antagonism by rimonabant in monkeys discriminating $\Delta^{9}$-THC, a single-dose apparent affinity estimate was calculated for individual monkeys with the following equation: $\mathrm{pK}_{\mathrm{B}}=-\log (\mathrm{B} /$ dose ratio -1$)$, with $\mathrm{B}$ expressed in moles per kilogram of body weight. Significant differences among $\mathrm{pK}_{\mathrm{B}}$ values were assessed with repeated-measures one-way analysis of variance (ANOVA). Time course data were converted to area under the function per animal, and differences among cannabinoid agonists were analyzed with repeated-measures one-way ANOVA followed by post-hoc Tukey's multiple comparison test $(P<0.05)$.

In $\Delta^{9}$-THC-treated monkeys discriminating rimonabant, the potencies of AM-2201, JWH-122, JWH-250, and CP-47,497 were calculated by expressing the mean shift in the rimonabant dose-response function (i.e., $\mathrm{ED}_{50}$ value of rimonabant determined in the presence of agonist divided by the $\mathrm{ED}_{50}$ of rimonabant alone) as a function of dose for individual monkeys. Linear regression of the individual data was used to estimate the dose of agonist producing a 2-fold rightward shift in the rimonabant dose-response function. Effects on response rate were examined with a one-way ANOVA separately per drug followed by post-hoc Tukey's multiple comparison tests. Linear regression was used to examine the relationship between the mean log-transformed $\mathrm{ED}_{50}$ values of synthetic cannabinoids for producing $\Delta^{9}$-THC-like discriminative stimulus effects and the mean log-transformed doses producing a 2-fold rightward shift in the rimonabant dose-effect function.

\section{Results}

Effects of AM-2201, JWH-122, JWH-250, and CP-47,497 in Rhesus Monkeys Discriminating $\boldsymbol{\Delta}^{\mathbf{9}}$-THC. AM-2201, JWH-122, CP-47,497, and JWH-250 dose-dependently increased mean $\Delta^{9}$-THC lever responding (Fig. 2, top left). AM-2201 and JWH122 produced $100 \%$ drug lever responding at a dose of $0.0032 \mathrm{mg} / \mathrm{kg}$; a larger dose $(0.1 \mathrm{mg} / \mathrm{kg})$ was required for $\Delta^{9}-\mathrm{THC}$, JWH-250, and CP-47,497 to produce $100 \%$ responding on the drug lever. After vehicle, mean responding on the $\Delta^{9}$-THC lever was $0 \%$ (Fig. 2, top left, leftmost symbols above vehicle). The slopes of the five doseresponse functions were not significantly different from each other $\left(\mathrm{F}_{4,39}=0.56 ; P=0.75\right)$. The $\mathrm{ED}_{50}$ values and $95 \%$ confidence limits calculated from the common slope are shown in Table 1. AM-2201 and JWH-122 were 10 - and 3.3-fold more potent than $\Delta^{9}$-THC, respectively, whereas CP-47,497 and JWH-250 were equipotent with $\Delta^{9}$-THC. Up to the largest doses tested, $\Delta^{9}$-THC, AM-2201, JWH-122, JWH-250, and CP-47,497 did not significantly modify response rate (Fig. 2, bottom left).

The duration of action of JWH-250, JWH-122, and AM-2201 to produce $\Delta^{9}$-THC lever responding was shorter than that of $\Delta^{9}$-THC and CP-47,497 $\left(\mathrm{F}_{4,15}=47.53 ; P<0.0001\right)$ (Fig. 2, top right). Monkeys switched from responding predominantly on the drug lever to the vehicle lever 1-2 hours after administration of AM-2201, JWH-122, and JWH-250 and 4-5 hours after CP-47,497 and $\Delta^{9}$-THC. The cannabinoid agonists did not significantly modify response rate as a function of time (Fig. 2, bottom right).
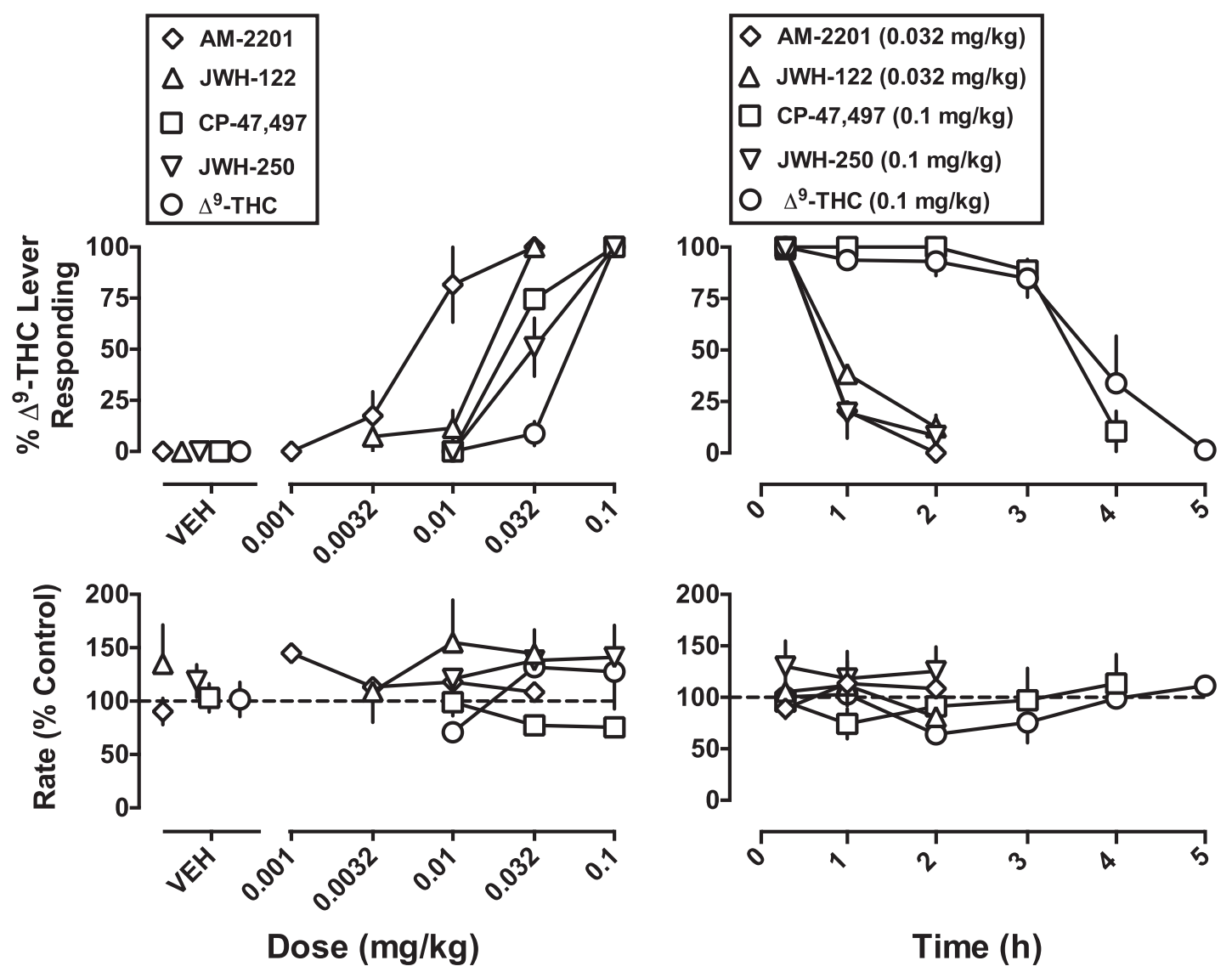

Time (h)

Fig. 2. Effects of AM-2201, JWH-122, CP-47,497, JWH-250, and $\Delta^{9}$-THC as a function of dose (left) and time (right) in rhesus monkeys discriminating $\Delta^{9}$-THC. Abscissae: vehicle (VEH) or dose in milligrams per kilogram of body weight (left) and time (right). Ordinates: mean ( \pm S.E.M.) percentage of responding on the $\Delta^{9}$-THC lever (top) and mean ( \pm S.E.M.) response rate expressed as a percentage of the control rate (bottom). 
TABLE 1

$\mathrm{ED}_{50}$ values, potency ratios, $\mathrm{pK}_{\mathrm{B}}$ values, and 95\% confidence limits (CLs) for AM-2201, JWH-122, CP-47,497, and JWH-250 in rhesus monkeys discriminating $\Delta^{9}$-THC $(0.1 \mathrm{mg} / \mathrm{kg}$ i.v. $)$

Potency ratios are the $\mathrm{ED}_{50}$ values of the agonist versus $\Delta^{9}-\mathrm{THC}$ or the $\mathrm{ED}_{50}$ values of the agonist in combination with rimonabant $(1 \mathrm{mg} / \mathrm{kg})$ divided by the $\mathrm{ED}_{50}$ value of the agonist alone.

\begin{tabular}{lccc}
\hline \multicolumn{1}{c}{ Drug alone } & $\mathrm{ED}_{50}$ Value $(95 \% \mathrm{CL})$ & Potency Ratio $(95 \% \mathrm{CL})$ & $\mathrm{pK}_{\mathrm{B}}(95 \% \mathrm{CL})$ \\
\hline$\Delta^{9}-\mathrm{THC}$ & $0.050(0.035-0.069)$ & & \\
AM-2201 & $0.005(0.002-0.013)$ & $10(3.4-16)$ versus $\Delta^{9}-\mathrm{THC}^{a}$ & \\
JWH-122 & $0.015(0.010-0.023)$ & $3.3(2.8-3.8)$ versus $\Delta^{9}-\mathrm{THC}^{a}$ & \\
CP-47,497 & $0.025(0.012-0.054)$ & $2.0(0.7-3.5)$ versus $\Delta^{9}-\mathrm{THC}$ & \\
JWH-250 & $0.033(0.021-0.053)$ & $1.5(0.7-2.4)$ versus $\Delta^{9}-\mathrm{THC}$ & \\
Drug in combination with rimonabant & & & \\
AM-2201 & $0.053(0.037-0.074)^{b}$ & $10.6(3.2-18.5)$ & $6.61(6.20-7.02)$ \\
JWH-122 & $0.161(0.108-0.239)^{b}$ & $10.7(9.9-11.3)$ & $6.65(6.62-6.69)$ \\
CP-47,497 & $0.274(0.119-0.631)^{b}$ & $11.0(9.7-11.9)$ & $6.66(6.61-6.71)$ \\
JWH-250 & $0.517(0.278-0.963)^{b}$ & $15.7(4.9-28.7)$ & $6.83(6.50-7.17)$ \\
\hline
\end{tabular}

${ }^{a}$ Significantly more potent than $\Delta^{9}$-THC.

${ }^{b}$ Significantly different from the $\mathrm{ED}_{50}$ values of the drugs alone.

Rimonabant $(1 \mathrm{mg} / \mathrm{kg})$ alone produced $0 \%$ responding on the $\Delta^{9}$-THC lever and antagonized the discriminative stimulus effects of each cannabinoid agonist (Fig. 3, left panels), as evidenced by significant increases in the $\mathrm{ED}_{50}$ value of each synthetic cannabinoid agonist. Table 1 shows the $\mathrm{ED}_{50}$ values of each synthetic cannabinoid agonist alone and in combination with rimonabant $(1 \mathrm{mg} / \mathrm{kg})$ and corresponding potency ratios. The single-dose apparent affinity estimates calculated for rimonabant were 6.61 in the presence of AM-2201, 6.65 in the presence of JWH-122, 6.66 in the presence of CP-47,497, and 6.83 in the presence of JWH-250. The $\mathrm{pK}_{\mathrm{B}}$ values calculated for each cannabinoid agonist were not significantly different from each other $\left(\mathrm{F}_{3,9}=0.34 ; P=0.79\right)$. Rate of responding was not significantly altered after rimonabant ( $1 \mathrm{mg} / \mathrm{kg}$ ) alone or in combination with AM-2201, JWH-122, CP-47,497, or JWH-250 (Fig. 3, right panels).

Effects of AM-2201, JWH-122, CP-47,497, and JWH-250 in $\Delta^{\mathbf{9}}$-THC-Treated Monkeys Discriminating Rimonabant. Rimonabant dose-dependently increased drug lever responding, with $0.1 \mathrm{mg} / \mathrm{kg}$ producing $0 \%$ responding on the drug lever and $1 \mathrm{mg} / \mathrm{kg}$ producing $100 \%$ responding on the drug lever (Fig. 4, left panels, circles). The $\mathrm{ED}_{50}$ value was $0.25 \mathrm{mg} / \mathrm{kg}$ when rimonabant was administered in cumulative doses (i.e., the control function for experiments with CP-47,497) and $0.21 \mathrm{mg} / \mathrm{kg}$ when rimonabant was administered in a single dose per test session (Table 2). Rimonabant alone did not significantly modify rate of responding (Fig. 4, right panels, circles). Vehicle resulted in $0 \%$ responding on the rimonabant lever. Administration of AM-2201 $(0.1 \mathrm{mg} / \mathrm{kg})$, JWH-122 $(0.32 \mathrm{mg} / \mathrm{kg}), \mathrm{CP}-47,497(0.32$ and $1 \mathrm{mg} / \mathrm{kg})$, and JWH-250 $(1 \mathrm{mg} / \mathrm{kg}) 6$ hours after $1 \mathrm{mg} / \mathrm{kg} \Delta^{9}$-THC produced $0 \%$ responding on the rimonabant lever. The largest doses of AM-2201 $(0.32 \mathrm{mg} / \mathrm{kg})$ and JWH-122 $(1 \mathrm{mg} / \mathrm{kg})$ produced emesis and ataxia. When synthetic cannabinoids were administered in the absence of rimonabant, response rate was significantly decreased to $14 \%$ of the vehicle control by $0.32 \mathrm{mg} / \mathrm{kg}$ AM- 2201 , $16 \%$ of the vehicle control by $1 \mathrm{mg} / \mathrm{kg}$ JWH- $122,16 \%$ of the vehicle control by $3.2 \mathrm{mg} / \mathrm{kg} \mathrm{CP}-47,497$, and $15 \%$ of the vehicle control by $3.2 \mathrm{mg} / \mathrm{kg} \mathrm{JWH}-250(P<0.05)$ (Fig. 4 , right panels, symbols above vehicle).

AM-2201, JWH-122, CP-47,497, and JWH-250 dosedependently attenuated the discriminative stimulus effects of rimonabant in monkeys receiving $1 \mathrm{mg} / \mathrm{kg} / 12$ hours $\Delta^{9}$-THC, as evidenced by significant increases in the $\mathrm{ED}_{50}$ value of rimonabant. Table 2 shows the $\mathrm{ED}_{50}$ values of rimonabant alone and in combination with a dose of synthetic cannabinoid agonist and corresponding potency ratios. Rimonabant significantly antagonized the rate-decreasing effects of each cannabinoid agonist. In the presence of rimonabant $(1 \mathrm{mg} / \mathrm{kg})$, AM-2201 $(0.32 \mathrm{mg} / \mathrm{kg})$ and JWH-122 $(1 \mathrm{mg} / \mathrm{kg})$ no longer produced emesis and ataxia.

The relationship between magnitude of shift in the rimonabant dose-response function and dose of cannabinoid agonist is shown in Fig. 5 (left). The slopes of the lines were not significantly different from each other $(P=0.20)$. Linear regression was used to estimate the dose of each agonist producing a 2-fold rightward shift in the rimonabant dose-response function; the doses were $0.06 \mathrm{mg} / \mathrm{kg}$ for AM-2201, $0.24 \mathrm{mg} / \mathrm{kg}$ for JWH-122, $0.44 \mathrm{mg} / \mathrm{kg}$ for CP-47,497, and $0.64 \mathrm{mg} / \mathrm{kg}$ for JWH-250. The relative potencies of AM-2201, JWH-122, CP-47,497, and JWH-250 to attenuate the rimonabant discriminative stimulus and substitute for the $\Delta^{9}$-THC discriminative stimulus were similar. This was also the case for JWH-018 and JWH-073, as replotted from Ginsburg et al. (2012). There was a significant positive correlation between doses of synthetic cannabinoid agonist producing a 2-fold rightward shift in the rimonabant doseresponse function and the $\mathrm{ED}_{50}$ values in substituting for the discriminative stimulus effects of $\Delta^{9}$-THC (Fig. $5 ; r^{2}=0.93$; $P<0.001)$.

\section{Discussion}

This study compared the pharmacology of the abused synthetic cannabinoids CP-47,497, AM-2201, JWH-122, and JWH-250. All four substituted for the discriminative stimulus effects of $\Delta^{9}$-THC. AM-2201 and JWH-122 were 10- and 3.3fold more potent than $\Delta^{9}$-THC, respectively, whereas JWH250, CP-47,497, and $\Delta^{9}-$ THC were equipotent. CP-47,497 and $\Delta^{9}$-THC had a similar duration of action ( $4-5$ hours), whereas that of AM-2201, JWH-122, and JWH-250 (1-2 hours) was shorter. Rimonabant $(1 \mathrm{mg} / \mathrm{kg})$ antagonized the discriminative stimulus and rate-decreasing effects of the agonists. Quantitative analysis of the magnitude of antagonism of discriminative stimulus effects by rimonabant was similar for all cannabinoid agonists tested. AM-2201, JWH-122, CP-47,497, and JWH-250 dose-dependently attenuated the discriminative stimulus effects of rimonabant in monkeys receiving $1 \mathrm{mg} / \mathrm{kg} / 12$ hours of $\Delta^{9}$-THC. These data show that three synthetic cannabinoids placed under schedule 1 of the 


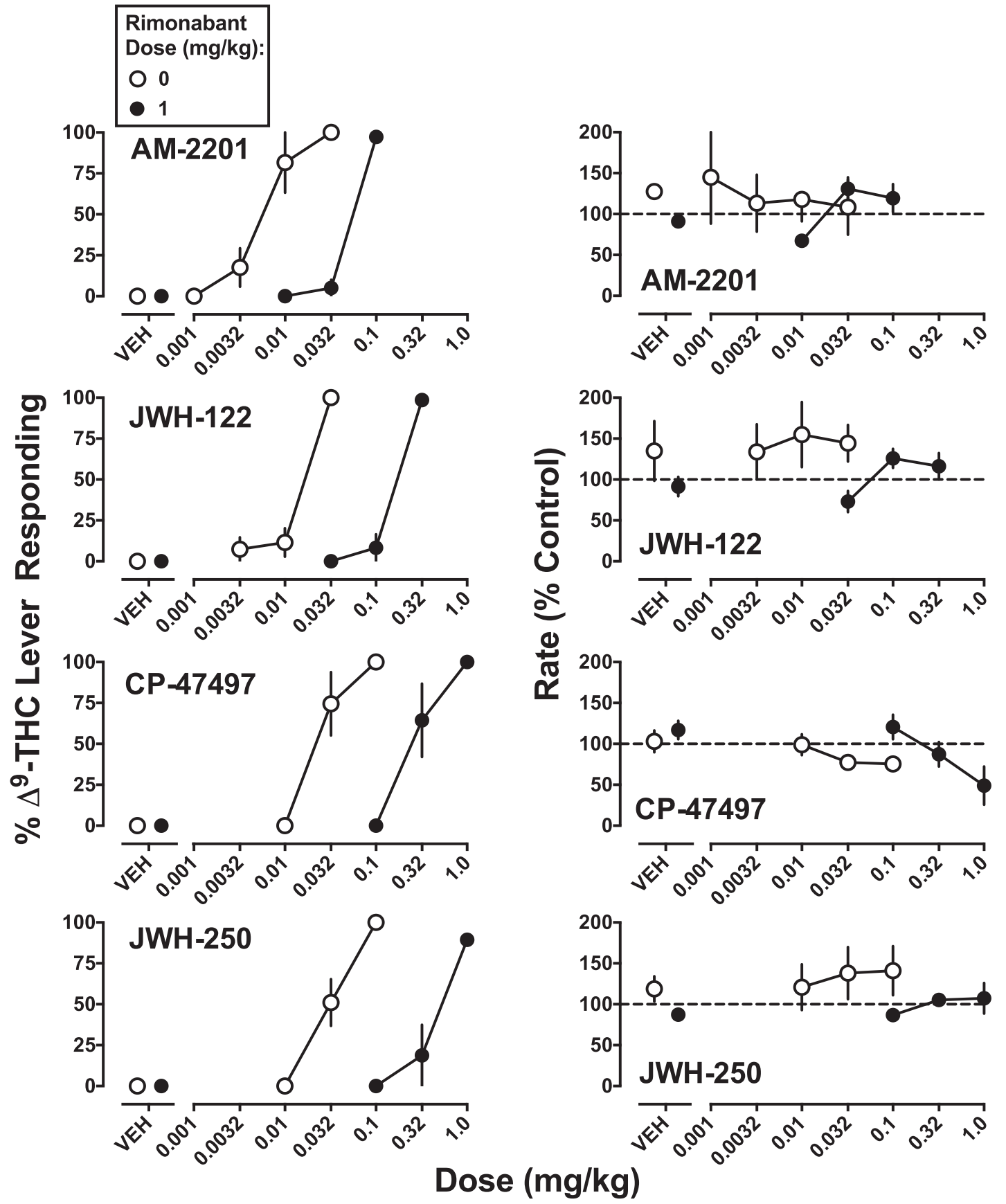

Fig. 3. Effects of AM-2201, JWH-122, CP-47,497, and JWH-250 in rhesus monkeys discriminating $\Delta^{9}{ }^{9}$ THC: antagonism by rimonabant. Abscissae: dose in milligrams per kilogram of body weight or vehicle (VEH). Ordinates: mean ( \pm S.E.M.) percentage of responding on the $\Delta^{9}-\mathrm{THC}$ lever (left) and mean ( \pm S.E.M.) response rate expressed as a percentage of the control rate (right). The control dose-response functions for AM-2201, JWH-122, CP-47,497, and JWH-250 are replotted from Fig. 1.

United States Controlled Substances Act (AM-2201, JWH122, and JWH-250) are more potent and/or have a shorter duration of action than $\Delta^{9}$-THC. However, all cannabinoids tested here appear to produce subjective effects through a common $\mathrm{CB}_{1}$ receptor mechanism, as evidenced by similar apparent affinity estimates calculated for rimonabant in their presence.

Before 2010, the synthetic cannabinoids JWH-018 and JWH-073 were the primary ingredients in Spice/K2 and related herbal blend products (Huffman et al., 1994; Huffman, 2009; Atwood et al., 2010). JWH-018 and JWH-073 were demonstrated to share discriminative stimulus effects with $\Delta^{9}$-THC in monkeys and mice (Ginsburg et al., 2012; Wiley et al., 2012). JWH-018 and JWH-073 were banned and replaced by various aminoalkylindole, phenacetylindole, and naphthoylpyrolle cannabinoids appropriated from the chemical libraries originally designed by J. W. Huffman and benzoylindole cannabinoids designed by A. Makriyannis (Hudson and Ramsey, 2011; Järbe et al., 2011; Carroll et al., 2012). The emergence of AM-2201, JWH-122, and JWH-250 as drugs of abuse occurred in the absence of extensive pharmacological and toxicological data. All three were eventually 

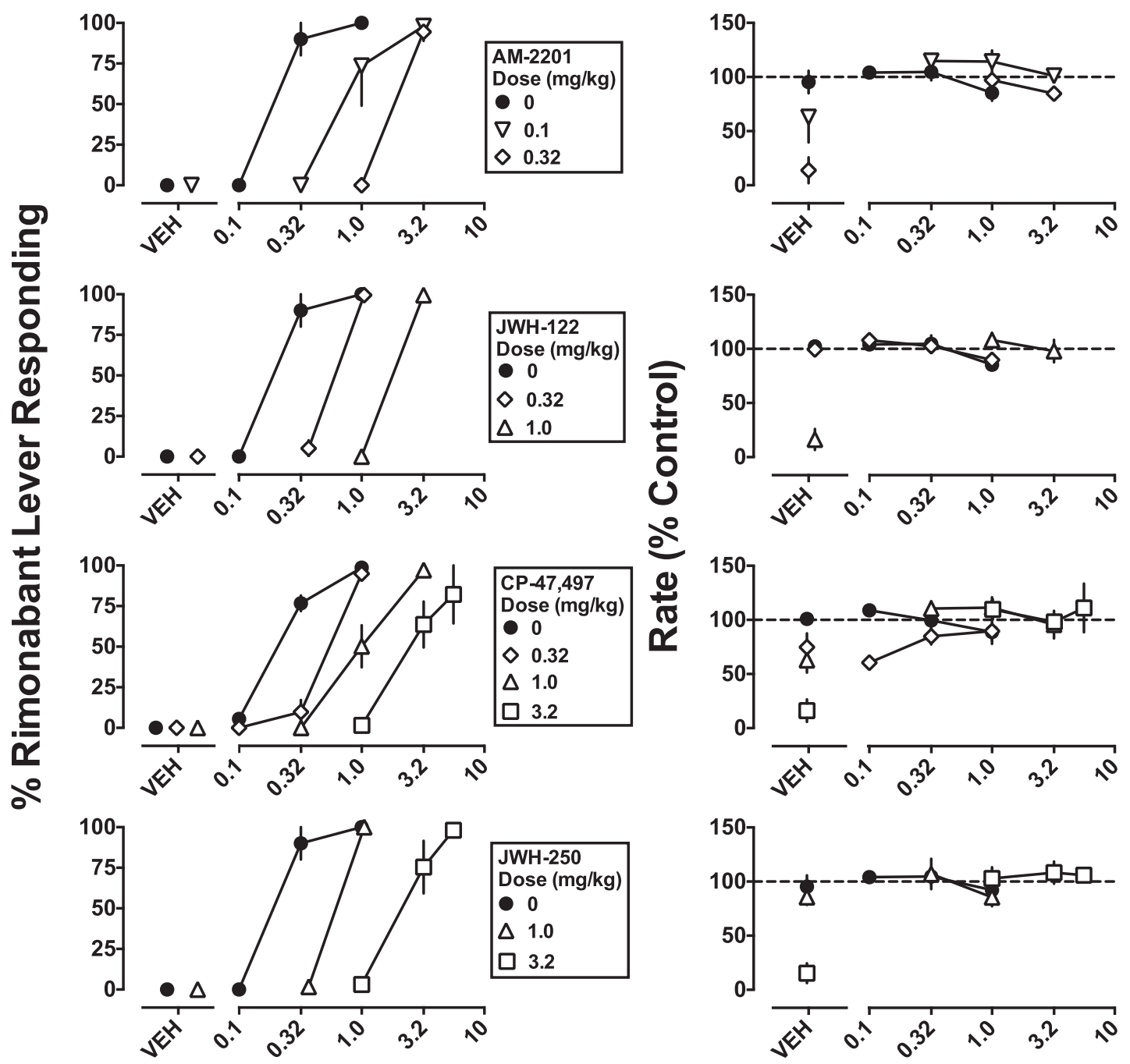

\section{Rimonabant Dose $(\mathrm{mg} / \mathrm{kg})$}

Fig. 4. Effects of AM-2201, JWH-122, CP-47,497, and JWH-250 in $\Delta^{9}$-THC-treated rhesus monkeys discriminating rimonabant. Abscissae: dose of rimonabant in milligrams per kilogram of body weight or vehicle (VEH). Ordinates: mean ( \pm S.E.M.) percentage of responding on the rimonabant lever (left) and mean ( \pm S.E.M.) response rate expressed as a percentage of the control rate (right).

shown to share discriminative stimulus effects with $\triangle^{9}$-THC in rats (Gatch and Forster 2014, 2016; Järbe et al., 2016). The current study extended the generality of these findings to nonhuman primates, and provided new information based on quantitative analyses of antagonism by rimonabant, including both prevention and reversal of discriminative stimulus effects.

TABLE 2

$\mathrm{ED}_{50}$ values and $95 \%$ confidence limits (CLs) for rimonabant, alone and in combination with AM-2201, JWH-122, CP-47,497, and JWH-250, in $\Delta^{9}$-THC-treated ( $1 \mathrm{mg} / \mathrm{kg} / 12$ hours) rhesus monkeys discriminating rimonabant $(1 \mathrm{mg} / \mathrm{kg}$ i.v.)

Potency ratios and $95 \% \mathrm{CLs}$ are the $\mathrm{ED}_{50}$ values of rimonabant in combination with the agonist divided by the $\mathrm{ED}_{50}$ value of rimonabant alone.

\begin{tabular}{ccc}
\hline Drug & ED $_{50}$ Value $(95 \% \mathrm{CL})$ & Potency Ratio (95\% CL) \\
\hline Rimonabant (cumulative dosing) & $0.25(0.16-0.39)$ & \\
+ CP 47,497 (0.32 mg/kg) & $0.51(0.37-0.71)^{a}$ & $2.0(1.2-3.6)$ \\
+ CP 47,497 (1.0 mg/kg) & $1.02(0.82-1.27)^{a}$ & $4.1(2.0-8.5)$ \\
+ CP 47,497 (3.2 mg/kg) & $2.66(1.92-3.68)^{a}$ & $10.6(2.9-39.3)$ \\
Rimonabant (single-bolus dosing) & $0.21(0.12-0.46)$ & \\
+ AM-2201 (0.1 mg/kg) & $0.77(0.44-1.33)^{a}$ & $3.7(1.6-8.3)$ \\
+ AM-2201 $(0.32 \mathrm{mg} / \mathrm{kg})$ & $1.88(1.67-2.11)^{a}$ & $9.0(1.8-42.4)$ \\
+ JWH-122 $(0.32 \mathrm{mg} / \mathrm{kg})$ & $0.49(0.36-0.67)^{a}$ & $2.3(1.3-4.1)$ \\
+ JWH-122 $(1.0 \mathrm{mg} / \mathrm{kg})$ & $1.80(1.78-1.82)^{a}$ & $8.6(1.8-38.8)$ \\
+ JWH-250 $(1.0 \mathrm{mg} / \mathrm{kg})$ & $0.56(0.54-0.58)^{a}$ & $2.7(1.3-5.2)$ \\
+ JWH-250 $(3.2 \mathrm{mg} / \mathrm{kg})$ & $2.21(1.74-2.82)^{a}$ & $10.5(3.4-31.5)$ \\
\hline
\end{tabular}

${ }^{a}$ Significantly different from rimonabant alone. 

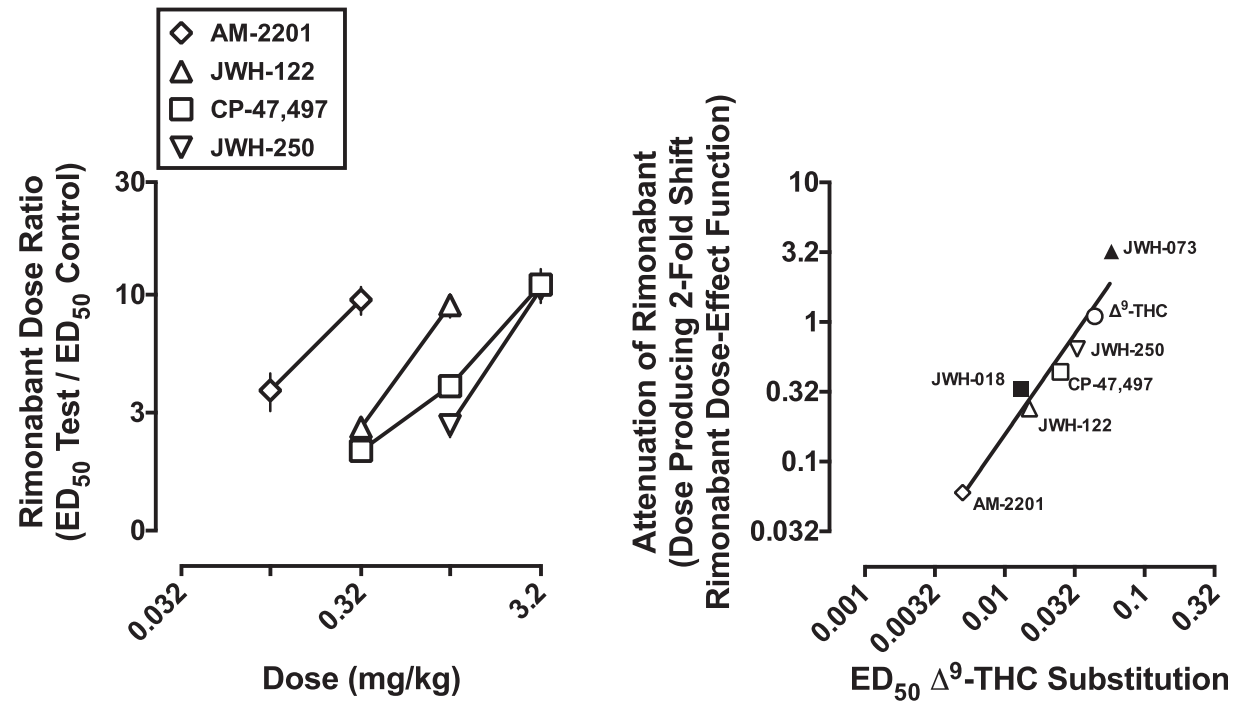

Fig. 5. Magnitude of rightward shift in the rimonabant dose-response function expressed as a function of AM-2201, JWH-122, CP-47,497, and JWH-250 dose (left) and correlation between dose of synthetic cannabinoid agonist producing a 2 -fold rightward shift in the rimonabant dose-effect function and $\mathrm{ED}_{50}$ value in substituting for the $\Delta^{9}$-THC discriminative stimulus (right). Left abscissa: dose in milligrams per kilogram of body weight. Left ordinate: mean $( \pm$ S.E.M.) rightward shift in the rimonabant dose-response function, calculated as the rimonabant $\mathrm{ED}_{50}$ value after pretreatment with a cannabinoid agonist divided by the control rimonabant $\mathrm{ED}_{50}$ value. Right abscissa and ordinate: dose in milligrams per kilogram of body weight expressed on a logarithmic scale. Data for JWH-018 and JWH-073 are summarized from data reported by Ginsburg et al. (2012).

The results of the current study demonstrated that AM-2201, JWH-122, JWH-250, and CP-47,497 shared discriminative stimulus effects with $\Delta^{9}$-THC; rank-order potency was AM-2201 < JWH-122 < JWH-250 = CP-47,497 $=\Delta^{9}$ THC. Weissman et al. (1982) showed that CP-47,497 was 7 -fold more potent than $\Delta^{9}$-THC in rats, which could reflect the differences in route of administration (i.v. versus i.p.) and species (monkeys versus rats). AM-2201, JWH-122, and JWH250 had a shorter duration of action (1-2 hours) than CP-47,497 and $\Delta^{9}$-THC (4-5 hours). Under experimental conditions identical to those of the current study, JWH-018 and JWH-073 had a duration of action of 1-2 hours (Ginsburg et al., 2012). Many cannabinoids from the JWH series, including JWH-122 and JWH-250, contain an indole ring, and AM-2201 is a benzoylindole that differs from JWH-018 by the presence of a fluorine atom in the pentyl chain (Nakajima et al., 2011). The bicyclic cannabinoid CP-47,497 has a longer duration of action (4-5 hours). An indole ring appears to confer a relatively short in vivo half-life, which is supported by previous results demonstrating that the aminoalkylindole WIN-55,212-2 [( $R$ )-(+)-[2,3-Dihydro-5methyl-3-(4-morpholinylmethyl)pyrrolo[1,2,3-de]-1,4-benzoxazin6-yl]-1-naphthalenylmethanone mesylate] has a short duration of action (i.e., 1-2 hours; Hruba and McMahon, 2014).

To identify the extent to which $\mathrm{CB}_{1}$ receptors mediate the effects of each agonist, they were studied in combination with rimonabant ( $1 \mathrm{mg} / \mathrm{kg})$. Rimonabant pretreatment resulted in surmountable antagonism of the discriminative stimulus effects of AM-2201, JWH-122, JWH-250, and CP-47,497. Under experimental conditions identical to the current study, rimonabant produced dose-dependent rightward shifts in the dose-response functions of other cannabinoid agonists (McMahon, 2009; Ginsburg et al., 2012). The results of Schild analysis from these previous studies suggested that antagonism was simple (i.e., at a single binding site), competitive, and reversible. The surmountable antagonism obtained at one dose of rimonabant here and elsewhere (McMahon, 2009) has been assumed to reflect a simple, competitive, and reversible interaction, i.e., the slope of a Schild plot was assumed to be not different from unity. Based on that assumption, a dose ratio calculated from a rightward shift is sufficient to calculate a single-dose apparent affinity estimate (i.e., $\mathrm{pK}_{\mathrm{B}}$ value). The
$\mathrm{pK}_{\mathrm{B}}$ values calculated for rimonabant in the presence of AM-2201, JWH-122, JWH-250, and CP-47,497 did not significantly differ from each other, nor did they differ from $\mathrm{pA}_{2}$ and $\mathrm{pK}_{\mathrm{B}}$ values determined previously in the presence of several other cannabinoid agonists (McMahon, 2006a, 2009; Ginsburg et al., 2012; Hruba and McMahon, 2014). Collectively, these results strongly suggest that a common receptor mechanism (i.e., $\mathrm{CB}_{1}$ ) mediates the capacity of drugs to substitute for the discriminative stimulus effects of intravenously administered $\Delta^{9}$-THC in rhesus monkeys.

A quantitative analysis of the capacity of an antagonist to reverse the effects of synthetic cannabinoids not only provides insight into receptor mechanisms of action, but also could inform novel clinical applications. In $\Delta^{9}$-THC-treated monkeys, pretreatment with AM-2201, JWH-122, JWH-250, and CP-47,497 resulted in a decrease in the potency of rimonabant to produce discriminative stimulus effects. That is, rimonabant reversed the effects of each synthetic cannabinoid. The capacity of rimonabant to reverse the effects of each synthetic cannabinoid was decreased as a function of increasing the dose of AM-2201, JWH-122, JWH-250, and CP-47,497. Figure 5 (left), which shows the magnitude of rightward shift in the rimonabant dose-effect function as a function of synthetic cannabinoid agonist dose, demonstrates that the relative potencies of AM-2201, JWH-122, JWH-250, and CP-47,497 are strikingly similar to their relative potencies in substituting for the discriminative stimulus effects of $\Delta^{9}$-THC [compare Fig. 5 (left) to Fig. 2 (top left)]. Collectively, these results demonstrate that rimonabant is equally effective in either preventing or reversing the effects of AM-2201, JWH-122, JWH-250, and CP-47,497. These data suggest that rimonabant could be an effective medication for reversing the $\mathrm{CB}_{1}$ receptor-mediated effects of synthetic cannabinoids. Although the use of rimonabant (Acomplia) for treatment of obesity-related illness was discontinued in 2009 due to concerns over adverse effects, its limited (i.e., acute) use to reverse synthetic cannabinoid overdose in emergency situations could prove beneficial.

Synthetic cannabinoids were originally synthesized as potential therapeutics (e.g., pain control); over time, they have become valuable research tools. Most recently, several synthetic cannabinoids have become drugs of abuse, and it is increasingly 
clear that many produce adverse effects that require emergency intervention. Vomiting and ataxia after intravenous administration of relatively large doses of AM-2201 and JWH-122 in the current study are consistent with toxicity. These adverse effects were not observed either when AM-2201 and JWH-122 were combined with rimonabant or after intravenous administration of JWH-250 and CP-47,497 alone. Toxicity could be especially problematic for high-potency synthetic cannabinoids, such as AM-2201 and JWH-122, insofar as the formulation of synthetic cannabinoids for human consumption does not account for differences in potency. Aside from differences in potency and duration of action, AM-2201, CP-47,497, JWH-122, and JWH250 had a strikingly similar $\mathrm{CB}_{1}$ receptor-mediated pharmacology. Strikingly similar antagonism of the discriminative stimulus effects and reversal of the disruptive effects of synthetic cannabinoids by rimonabant provide evidence for a novel clinical approach for treating the adverse effects of synthetic cannabinoid overdose.

\section{Acknowledgments}

The authors are grateful to A. Zaki and D. Schulze for technical assistance, and to Drs. Andrew Coop and M. Imran Ansari for creating Fig. 1. The corresponding author acknowledges the late Dr. Torbjörn U. C. Järbe and his pioneering use of drug discrimination as a method for unraveling the neurobiology of cannabinoids.

\section{Authorship Contributions}

Participated in research design: Hruba, McMahon.

Conducted experiments: Hruba.

Performed data analysis: Hruba, McMahon.

Wrote or contributed to the writing of the manuscript: Hruba, McMahon.

\section{References}

Atwood BK, Huffman J, Straiker A, and Mackie K (2010) JWH018, a common constituent of 'Spice' herbal blends, is a potent and efficacious cannabinoid CB receptor agonist. $\mathrm{Br} J$ Pharmacol 160:585-593.

Auwärter V, Dresen S, Weinmann W, Müller M, Pütz M, and Ferreirós N (2009) 'Spice' and other herbal blends: harmless incense or cannabinoid designer drugs? J Mass Spectrom 44:832-837.

Carroll FI, Lewin AH, Mascarella SW, Seltzman HH, and Reddy PA (2012) Designer drugs: a medicinal chemistry perspective. Ann N Y Acad Sci 1248:18-38.

Drug Enforcement Administration (2011) Schedules of controlled substances: temporary placement of five synthetic cannabinoids into schedule I. Fed Reg $\mathbf{7 6}$ 11075-11078.

Gatch MB and Forster MJ (2014) $\Delta^{9}$-Tetrahydrocannabinol-like discriminative stimulus effects of compounds commonly found in K2/Spice. Behav Pharmacol 25 : $750-757$.

Gatch MB and Forster MJ (2016) $\Delta\left({ }^{9}\right)$-Tetrahydrocannabinol-like effects of novel synthetic cannabinoids in mice and rats. Psychopharmacology (Berl) 233 1901-1910.

Ginsburg BC, Schulze DR, Hruba L, and McMahon LR (2012) JWH-018 and JWH073: $\Delta^{9}$-tetrahydrocannabinol-like discriminative stimulus effects in monkeys. $J$ Pharmacol Exp Ther 340:37-45.

Hruba L and McMahon LR (2014) The cannabinoid agonist HU-210: pseudo-irreversible discriminative stimulus effects in rhesus monkeys. Eur J Pharmacol 727:35-42.

Hudson S and Ramsey J (2011) The emergence and analysis of synthetic cannabinoids. Drug Test Anal 3:466-478.

Huffman JW (2009) Cannabinomimetic indoles, pyrroles and indenes: structureactivity relationships and receptor interactions, in The Cannabinoid Receptors (Regio PH ed) Vol. 1, pp 49-94, Humana Press, New York.
Huffman JW, Dai D, Martin BR, and Compton DR (1994) Design, synthesis and pharmacology of cannabinomimetic indoles. Bioorg Med Chem Lett 4:563-566.

Huffman JW, Mabon R, Wu MJ, Lu J, Hart R, Hurst DP, Reggio PH, Wiley JL, and Martin BR (2003) 3-Indolyl-1-naphthylmethanes: new cannabimimetic indoles provide evidence for aromatic stacking interactions with the $\mathrm{CB}\left({ }_{1}\right)$ cannabinoid receptor. Bioorg Med Chem 11:539-549.

Huffman JW, Szklennik PV, Almond A, Bushell K, Selley DE, He H, Cassidy MP, Wiley JL, and Martin BR (2005) 1-Pentyl-3-phenylacetylindoles, a new class of cannabimimetic indoles. Bioorg Med Chem Lett 15:4110-4113.

Institute of Laboratory Animal Resources (2011) Guide for the Care and Use of Laboratory Animals, 8th ed, Institute of Laboratory Animal Resources, Commission on Life Sciences, National Research Council, Washington, DC.

Järbe TU, Deng H, Vadivel SK, and Makriyannis A (2011) Cannabinergic aminoalkylindoles, including AM678=JWH018 found in 'Spice', examined using drug $\left(\Delta\left({ }^{9}\right)\right.$-tetrahydrocannabinol $)$ discrimination for rats. Behav Pharmacol 22:498-507.

Järbe TU, Gifford RS, Zvonok A, and Makriyannis A (2016) [INCREMENT]9Tetrahydrocannabinol discriminative stimulus effects of AM2201 and related aminoalkylindole analogs in rats. Behav Pharmacol 27:211-214.

Kenakin TP (1997) Pharmacologic Analysis of Drug-Receptor Interaction, 3rd ed, Raven Press, New York.

Lapoint J, James LP, Moran CL, Nelson LS, Hoffman RS, and Moran JH (2011) Severe toxicity following synthetic cannabinoid ingestion. Clin Toxicol (Phila) 49:760-764.

Makriyannis A and Deng H (2001) inventors, University of Connecticut, assignee. Cannabimimetic indole derivatives. U.S. patent US00/28832 1-25

Makriyannis A and Deng H (2007) inventors, Makriyannis A and Deng H, assignee. Cannabimimetic indole derivatives. U.S. patent US20080090871A1.

McMahon LR (2006a) Characterization of cannabinoid agonists and apparent pA2 analysis of cannabinoid antagonists in rhesus monkeys discriminating $\Delta^{9}$-tetrahydrocannabinol. $J$ Pharmacol Exp Ther 319:1211-1218.

McMahon LR (2006b) Discriminative stimulus effects of the cannabinoid CB1 antagonist SR 141716A in rhesus monkeys pretreated with $\Delta^{9}$-tetrahydrocannabinol. Psychopharmacology (Berl) 188:306-314.

McMahon LR (2009) Apparent affinity estimates of rimonabant in combination with anandamide and chemical analogs of anandamide in rhesus monkeys discriminating $\Delta^{9}$-tetrahydrocannabinol. Psychopharmacology (Berl) 203:219-228.

Nakajima J, Takahashi M, Nonaka R, Seto T, Suzuki J, Yoshida M, Kanai C, and Hamano $\mathrm{T}$ (2011) Identification and quantitation of a benzoylindole (2-methoxyphenyl)(1-pentyl$1 \mathrm{H}$-indol-3-yl)methanone and a naphthoylindole 1-(5-fluoropentyl-1H-indol-3-yl)(naphthalene-1-yl)methanone (AM-2201) found in illegal products obtained via the Internet and their cannabimimetic effects evaluated by in vitro [35S]GTP $\gamma \mathrm{S}$ binding assays. Forensic Toxicol 29:132-141.

Palmer SL, Thakur GA, and Makriyannis A (2002) Cannabinergic ligands. Chem Phys Lipids 121:3-19.

Rodriguez JS and McMahon LR (2014) JWH-018 in rhesus monkeys: differential antagonism of discriminative stimulus, rate-decreasing, and hypothermic effects. Eur J Pharmacol 740:151-159.

Rosenbaum CD, Carreiro SP, and Babu KM (2012) Here today, gone tomorrow... and back again? A review of herbal marijuana alternatives (K2, Spice), synthetic cathinones (bath salts), kratom, Salvia divinorum, methoxetamine, and piperazines. J Med Toxicol 8:15-32.

Seely KA, Patton AL, Moran CL, Womack ML, Prather PL, Fantegrossi WE, RadominskaPandya A, Endres GW, Channell KB, Smith NH, et al. (2013) Forensic investigation of K2, Spice, and "bath salt" commercial preparations: a three-year study of new designer drug products containing synthetic cannabinoid, stimulant, and hallucinogenic compounds. Forensic Sci Int 233:416-422.

Simmons J, Cookman L, Kang C, and Skinner C (2011) Three cases of "spice" exposure. Clin Toxicol (Phila) 49:431-433.

Stewart JL and McMahon LR (2010) Rimonabant-induced $\Delta^{9}$-tetrahydrocannabinol withdrawal in rhesus monkeys: discriminative stimulus effects and other withdrawal signs. J Pharmacol Exp Ther 334:347-356.

Tallarida RJ (2000) Drug Synergism and Dose-Effect Data Analysis, Chapman and Hall/CRC, Boca Raton, FL.

Vardakou I, Pistos C, and Spiliopoulou Ch (2010) Spice drugs as a new trend: mode of action, identification and legislation. Toxicol Lett 197:157-162.

Weissman A, Milne GM, and Melvin, JrLS (1982) Cannabimimetic activity from CP-47,497, a derivative of 3-phenylcyclohexanol. J Pharmacol Exp Ther 223: $516-523$.

Wiley JL, Marusich JA, Martin BR, and Huffman JW (2012) 1-Pentyl-3phenylacetylindoles and JWH-018 share in vivo cannabinoid profiles in mice. Drug Alcohol Depend 123:148-153.

Address correspondence to: Dr. Lance R. McMahon, Department of Pharmacology, University of Texas Health San Antonio, 7703 Floyd Curl Drive, San Antonio, TX 78229-3900. E-mail: mcmahonl@uthscsa.edu 